\title{
Beneficial effects of brain-derived neurotropic factor on in vitro maturation of porcine oocytes
}

\author{
Eugine Lee ${ }^{1,2}$, Yeon Ik Jeong ${ }^{1,2}$, Seon Mi Park ${ }^{1}$, Jong Yun Lee ${ }^{1,2}$, Ji Hye Kim ${ }^{1,2}$, Sun Woo Park ${ }^{1,3}$, \\ M S Hossein ${ }^{1}$, Yeon Woo Jeong ${ }^{1,2}$, Sue Kim ${ }^{1}$, Sang Hwan Hyun ${ }^{1,3}$ and Woo Suk Hwang ${ }^{1}$ \\ ${ }^{1}$ SooAm Biotech Research Foundation, Sooambuilding 1027-4, Bangbae3-dong, Seocho-gu, Seoul 137-851, South \\ Korea, ${ }^{2}$ Department of Theriogenology and Biotechnology, College of Veterinary Medicine, Seoul National University, \\ Seoul 151-742, South Korea and ${ }^{3}$ Laboratory of Veterinary Biotechnology, College of Veterinary Medicine, Chunbuk \\ National University, Cheongju 361-763, South Korea
}

Correspondence should be addressed to W-S Hwang; Email: hwangws@sooam.org

\begin{abstract}
In an effort to improve the quality of in vitro produced porcine embryos, we investigated the effect of brain-derived neurotropic factor (BDNF), a neurotropin family member, on in vitro maturation (IVM) of porcine oocytes. The expression of BDNF and truncated isoforms of its receptor, tyrosine kinase B (TrkB), and p75 common neurotropin receptor was detected in both follicular cells and metaphase-I stage oocytes by RT-PCR. However, mRNA of full-length TrkB was not found in oocytes although it was detected in follicular cells. The expression pattern of BDNF and TrkB was confirmed by immunohistochemistry. Supplementation with BDNF $(30 \mathrm{ng} / \mathrm{ml})$ during IVM significantly $(P<0.05)$ increased the first polar body extrusion and glutathione levels in oocytes, whereas the effect of BDNF on nuclear maturation was diminished when gonadotropin and epidermal growth factor (EGF) were added to the culture media. However, treatment with BDNF $(30 \mathrm{ng} / \mathrm{ml})$ along with EGF $(10 \mathrm{ng} / \mathrm{ml})$ in the presence of gonadotropin significantly $(\boldsymbol{P}<\mathbf{0 . 0 5})$ increased the developmental competence of oocytes to the blastocyst stage after both in vitro fertilization (IVF; $29.1 \%$ when compared with control, 15.6\%) and somatic cell nuclear transfer (SCNT; 13.6\% when compared with control, $3 \%$ ). This appeared to reflect a stimulatory interaction between BDNF and EGF to enhance the cytoplasmic maturation of oocytes to support successful preimplantation development. In conclusion, BDNF enhanced nuclear and cytoplasmic maturation of oocytes by autocrine and/or paracrine signals. Also, when used together with EGF, BDNF increased the developmental potency of embryos after IVF and SCNT, demonstrating an improved in vitro production protocol for porcine oocytes.
\end{abstract}

Reproduction (2007) 134 405-414

\section{Introduction}

Recent advances in biotechnology have enabled the production of cloned or genetically modified pigs by manipulation of in vitro produced embryos. Notably, however, the overall efficiency of this process is still extremely low and the quality of embryos produced in vitro is inferior to those produced in vivo. One of the major problems includes improper in vitro maturation (IVM) of oocytes, in both the nuclear and the cytoplasmic compartments. Although porcine IVM technology and molecular aspects of pig oocytes have been well studied and reviewed (Day 2000, Nagai 2001, Sun \& Nagai 2003), there is a paucity of information on ovarian factors that may be important for oocyte maturation and subsequent development.

Neurotropins (NTs), including nerve growth factor (NGF), brain-derived neurotropic factor (BDNF) and NTs
3 and 4 (NT3/4), comprise a family of soluble polypeptide growth factors widely recognized for their essential roles in the differentiation and survival of defined neuronal populations of the central and peripheral nervous systems (Jones et al. 1994). However, both NTs and their receptors also play important roles in nonneuronal tissues, including the endocrine system. Several NTs and their respective receptor tyrosine kinases (Trk-) have been found to be expressed in the mammalian ovary (Dissen etal. 1996) and play a direct role in the regulation of early follicular development and ovulation (Dissen et al. 2002, Spears etal. 2003). BDNF is a NT family member, which is known to be important for early follicular development in mice through activation of the high-affinity TrkB receptor and the low-affinity p75 NT receptor (NTR; Ojeda et al. 2000, Paredes et al. 2004). It has been reported that BDNF was detected in human follicular fluid and the site of secretion appears to be cumulus granulosa cells. Moreover, the 
authors suggested a possible role for BDNF in the regulation of oocyte nuclear maturation through mouse study (Seifer et al. 2002a,2002b). A recent study demonstrated that BDNF from granulosa and cumulus cells enhanced first polar body extrusion and increased the competence of mouse oocytes to complete preimplantation development in vivo and in vitro (Kawamura et al. 2005). Furthermore, maturation of oocytes in the presence of BDNF promoted the preimplantational development of bovine embryos (Martins da Silva et al. 2005).

On this basis, we hypothesized that BDNF could be one of several factors secreted from follicular cells that function to enhance porcine oocyte maturation. In the present study, we investigated the effect of BDNF supplementation during IVM on oocyte maturation and subsequent embryo development after in vitro fertilization (IVF) and somatic cell nuclear transfer (SCNT).

\section{Materials and Methods}

\section{IVM and evaluation of first polar body extrusion in pig oocytes}

Ovaries were retrieved from prepubertal gilts at a local slaughterhouse and transported to the laboratory within $2 \mathrm{~h}$. Follicular fluid and cumulus-oocyte complexes (COCs) from follicles 3-6 mm in diameter were aspirated using an 18-gauge needle attached to a $10 \mathrm{ml}$ disposable syringe. Each group of 50 COCs was selected and cultured in $500 \mu \mathrm{l}$ tissue culture medium (TCM)-199 (Life Technologies) at $39{ }^{\circ} \mathrm{C}$ in a humidified atmosphere of $5 \% \mathrm{CO}_{2}$ and $95 \%$ air with different experimental designs. At the end of maturation culture, COCs were transferred to HEPESbuffered NCSU-23 medium containing $0.5 \mathrm{mg} / \mathrm{ml}$ hyaluronidase (Sigma-Aldrich Corp.) for $1 \mathrm{~min}$ and the cumulus cells were subsequently removed by gentle pipetting. Oocytes were then stained with $5 \mu \mathrm{g} / \mathrm{ml}$ bisbenzimide (Hoechst 33 342, Sigma) for 5 min and the occurrence of first polar body extrusion was observed under an inverted microscope equipped with epifluorescence.

\section{IVF}

At $44 \mathrm{~h}$ of IVM, oocytes freed from cumulus cells were washed in modified Tris-buffered medium (mTBM) containing $113.1 \mathrm{mM} \mathrm{NaCl}, 3 \mathrm{mM} \mathrm{KCl}, 7.5 \mathrm{mM}$ $\mathrm{CaCl}_{2} \cdot 2 \mathrm{H}_{2} \mathrm{O}, 20 \mathrm{mM}$ Tris, $11 \mathrm{mM}$ glucose, $5 \mathrm{mM}$ sodium pyruvate and $0.1 \%(\mathrm{w} / \mathrm{v}) \mathrm{BSA}$, and co-incubated with $2 \times$ $10^{6}$ spermatozoa/ml in $50 \mu$ d droplets (20 oocytes per drop) of mTBM covered with mineral oil in $5 \% \mathrm{CO}_{2}$ in air at $39{ }^{\circ} \mathrm{C}$ for $6 \mathrm{~h}$. After IVF, the oocytes were washed and transferred into in vitro culture (IVC) medium.

\section{Preparation of donor cells}

Fetal fibroblasts were isolated from slaughterhousederived fetuses at $\sim 40$ days of gestation. The head of the fetus was removed using iris scissors and soft tissues such as liver and intestine were discarded by scooping out with two watchmaker's forceps. After washing twice with PBS, the carcass was minced with a surgical blade on a $100 \mathrm{~mm}$ culture dish (Becton Dickinson, Lincoln Park, NJ, USA). The minced fetal tissues were dissociated in DMEM (Life Technologies) supplemented with $0.1 \%$ $(\mathrm{w} / \mathrm{v})$ trypsin/1 mM EDTA (Life Technologies) for 1-2 $\mathrm{h}$. Trypsinized cells were washed once by centrifugation at $300 \mathrm{~g}$ for $10 \mathrm{~min}$ and subsequently seeded into $100 \mathrm{~mm}$ plastic culture dishes. Seeded cells were subsequently cultured for 6-8 days in DMEM supplemented with 10\% $(\mathrm{v} / \mathrm{v})$ fetal bovine serum (FBS; Life Technologies), $1 \mathrm{mM}$ sodium pyruvate, $1 \%(\mathrm{v} / \mathrm{v})$ nonessential amino acids (Life Technologies), and $10 \mu \mathrm{g} / \mathrm{ml}$ penicillin/streptomycin solution (Life Technologies) at $39{ }^{\circ} \mathrm{C}$ in a humidified atmosphere of $5 \% \mathrm{CO}_{2}$ and $95 \%$ air. After removal of unattached clumps of cells or explants, attached cells were subcultured at intervals of 5-7 days by trypsinization for 5 min using $0.1 \%$ trypsin and $0.02 \%$ EDTA. Donor cells cultured until confluent were retrieved from the monolayer by trypsinization and subsequently used for SCNT.

\section{SCNT}

The zonae pellucidae of oocytes were partially dissected using a fine glass needle and the first polar body and adjacent cytoplasm, presumably containing the metaphaseII (MII) chromosomes, were extruded by squeezing with the same needle. Oocytes were then stained with $5 \mu \mathrm{g} / \mathrm{ml}$ bisbenzimide (Hoechst 33 342) for $5 \mathrm{~min}$ and observed under an inverted microscope equipped with epifluorescence. Oocytes still containing DNA material were excluded. A single donor cell with a smooth cytoplasmic membrane was introduced into the perivitelline space of an enucleated oocyte. Couplets were placed in a $0.3 \mathrm{M}$ mannitol solution containing $0.5 \mathrm{mM}$ HEPES, $0.1 \mathrm{mM}$ $\mathrm{CaCl}_{2}$, and $0.1 \mathrm{mM} \mathrm{MgCl}$ for 4 min and transferred to a chamber consisting of two electrodes overlaid with fusion and activation solution. Couplets were fused and activated simultaneously with a single direct current pulse $2.0 \mathrm{kV} / \mathrm{cm}$ for $50 \mu$ sec using a BTX Electro-cell Manipulator 2001 (BTX Inc., San Diego, CA, USA). All treated embryos were washed thrice with NCSU-23 supplemented with $4 \mathrm{mg} / \mathrm{ml}$ BSA, transferred into IVC medium.

\section{Embryo culture}

Embryos were placed in $25 \mu \mathrm{l}$ microdrops (five to seven oocytes per drop) of IVC medium under mineral oil and cultured at $39^{\circ} \mathrm{C}$ in a $5 \% \mathrm{CO}_{2}, 5 \% \mathrm{O}_{2}$, and $90 \% \mathrm{~N}_{2}$ atmosphere. The base IVC medium for pig embryos was $\mathrm{mNCSU}-23$, which contains $0.5 \mathrm{mM}$ pyruvate $/ 5 \mathrm{mM}$ lactate as energy sources (instead of glucose) and also contains $0.4 \%$ BSA (Kim et al. 2004). The day of insemination or injection of donor cells into enucleated 
oocytes was defined as day 0 . The rates of cleavage and blastocyst formation were evaluated under a stereomicroscope at days 2 and 7 respectively.

\section{Total RNA isolation and RT-PCR amplification}

MI stage oocytes and cumulus cells were obtained $22 \mathrm{~h}$ after IVM and mural granulosa cells were isolated from aspirated follicular fluid. Total RNA extraction from each sample and RT was carried out as reported previously (Lee et al. 2005). The primers for $\beta$-actin and BDNF were designed based on Sus scrofa $\beta$-actin mRNA (accession number: U07786) and BDNF mRNA (accession number: X16413). Because the complete mRNA sequences of Sus scrofa TrkB and p75 NTR are not known, primers reported in human (Anderson et al. 2002, Martins da Silva et al. 2005), and mouse studies (Kawamura et al. 2005) were used in this study. The primers for BDNF, full-length TrkB, truncated TrkB (trTrkB), p75 NTR and $\beta$-actin were as follows: BDNF: sense 5'-ACATGTATACGTCCCGAGTC-3', antisense 5'-TATCCTTATGAACCGCCAGC-3'; TrkB: sense 5'-GGCCCAGATGCTGTCATTAT-3', antisense 5'-TCCTGCTCAGGACAGAGGTT-3'; trTrkB: sense 5'-CATGTTACCAATCACACGGAGTA-3', antisense 5'-CCATCCAGTGGGATCTTATGAAA-3'; p75 NTR: sense 5-GTGGAGATGGAGATGATATGGAA-3', antisense $5^{\prime}$-GAAGGCAATCTCCAATTAGAAGC- ${ }^{\prime}$; $\beta$-actin: sense $5^{\prime}$-CGAAGCTGGACAAGGAGAAG-3', antisense 5'-CTCCAGGTTGCCTCTCACTC-3'.

The cDNA $(5 \mu \mathrm{l})$ was amplified in a $50 \mu \mathrm{l}$ PCR containing 1.25 units hot start Taq polymerase and its buffer, $1.5 \mathrm{mM} \mathrm{MgCl} 2,2 \mathrm{mM}$ dNTP, and $25 \mathrm{pmol}$ specific primers. The PCR amplification was carried out for one cycle with denaturing at $95{ }^{\circ} \mathrm{C}$ for $15 \mathrm{~min}$, and 35 subsequent cycles with denaturing at $95^{\circ} \mathrm{C}$ for $30 \mathrm{~s}$, annealing at $53{ }^{\circ} \mathrm{C}$ for $30 \mathrm{~s}$, extension at $72{ }^{\circ} \mathrm{C}$ for $30 \mathrm{~s}$, and a final extension at $72{ }^{\circ} \mathrm{C}$ for $15 \mathrm{~min}$. Amplified PCR products $(10 \mu \mathrm{l})$ were fractionated on a $0.8 \%$ agarose gel, stained with ethidium bromide, and visualized with a Gel Documentation system (GelDocTM 2000, Bio-Rad). The PCR products were purified from the gel with an agarose gel extraction kit (Qiagen) and cloned into the pCRTopo cloning vector (Life Technologies). Sequence analysis was performed to confirm the identity of amplified PCR products using an automated DNA sequence analyzer (ABI 3100, Applied Biosystems, Foster City, CA, USA).

\section{Immunohistochemistry}

Immunofluorescence-based detection of BDNF and TrkB was performed by using denuded MI stage oocytes, harvested $22 \mathrm{~h}$ after IVM. After removing cumulus cells, denuded oocytes were fixed with $4 \%$ paraformaldehyde for $20 \mathrm{~min}$. After permeabilization with $0.1 \%$ Tween-20 and $1 \%$ Triton-X, nonspecific binding was blocked with
$1 \%$ normal goat serum. Oocytes were then incubated with rabbit anti-BDNF (sc-546, Santa Cruz Biotech. Inc., Santa Cruz, CA, USA) or rabbit anti-TrkB antibodies (sc-12, Santa Cruz) at a ratio of 1:200 dilution overnight. Oocytes incubated in the absence of primary antibody were used as a negative control. After extensive washing, oocytes were placed in goat anti-rabbit secondary antibody conjugated with fluorescein isothiocyanate (FITC; Santa Cruz) at a ratio of 1:700 dilution for $3 \mathrm{~h}$. After washing, oocytes were counterstained with $100 \mu \mathrm{g} / \mathrm{ml}$ fluorochrome propidium iodide (PI; Sigma) for $10 \mathrm{~min}$, mounted on a drop of PBS containing $0.5 \%$ FBS and examined under a confocal microscope (Radiance 2000, Bio-Rad). Cumulus cells were cultured on slides, fixed and stained for BDNF and TrkB, as outlined above.

\section{Glutathione assay}

After 44 h IVM in TCM-199 supplemented with 10\% (v/v) porcine follicular fluid (pFF), with or without different doses of BDNF, the amount of glutathione (GSH) in the oocytes was assayed using a previously described microglutathione assay (Baker et al. 1990), with slight modifications. Briefly, denuded oocytes were washed thrice in PBS, and groups of 30-40 oocytes in $5 \mu \mathrm{l}$ PBS were transferred to $1.5 \mathrm{ml}$ Eppendorf tubes. The samples were frozen at $-70{ }^{\circ} \mathrm{C}$ and thawed at room temperature thrice and $5 \mu \mathrm{l} 1.25 \mathrm{M} \mathrm{H}_{3} \mathrm{PO}_{4}$ (Sigma) was added. The tubes were centrifuged at $1200 \mathrm{~g}$ for $10 \mathrm{~min}$ and the supernatants were transferred to a 96-well microtiter plate $(50 \mu \mathrm{l} /$ well). A $100 \mu \mathrm{l}$ reaction mixture consisting of $5 \mathrm{ml}$ 5,50-dithiobis(2)-nitrobenzoic acid (D8130, Sigma; $1 \mathrm{mM}), 5 \mathrm{ml}$ NADPH (N7505, Sigma; $1 \mathrm{mM}), 5.75 \mathrm{ml}$ NaPO4 buffer $(100 \mathrm{mM})$, and $0.1 \mathrm{ml} \mathrm{GSH}$ reductase (G3664, Sigma; $200 \mathrm{U} / \mathrm{ml}$ ) was added and the plate was immediately placed in a microtiter plate reader (Bio-Rad). The formation of 5-thio-2-nitrobenzoic acid was monitored every $30 \mathrm{~s}$ for $3 \mathrm{~min}$. Standards were prepared for each assay, and GSH content per sample was determined from a standard curve (Sigma plot/enzyme kinetics). The GSH concentrations (pmol/oocyte) were calculated by dividing the total concentration per sample by the number of oocytes present in the sample.

\section{Blastocyst cell counting}

Blastocysts were fixed in $4 \%$ of paraformaldehyde on day 7 of culture, and stained with $5 \mu \mathrm{g} / \mathrm{ml}$ bisbenzimide (Hoechst 33 342) for 5 min. After three washes in PBS, individual blastocysts were mounted and their cell number was assessed using epifluorescence microscopy.

\section{Experimental design}

In experiment 1, COCs were matured in TCM-199 supplemented with $0.1 \%$ polyvinyl alcohol (PVA) for 
Table 1 In vitro maturation (IVM) conditions used in experiment 2.

\begin{tabular}{lll}
\hline & \multicolumn{2}{c}{ IVM $^{\mathbf{a}}$} \\
\cline { 2 - 3 } & \multicolumn{1}{c}{$0-22 \mathrm{~h}$} & $22-44 \mathrm{~h}$ \\
\hline EGF $(-)$ & GTH & BDNF \\
& GTH+BDNF & BDNF \\
& GTH & - \\
EGF $(+)$ & BDNF & BDNF \\
& GTH & BDNF \\
& GTH BDNF & BDNF \\
& BDNF & - \\
& & BDNF \\
\hline
\end{tabular}

a Basically, COCs were cultured in TCM-199 supplemented with $10 \%$ pFF. The concentrations of supplements are EGF, $10 \mathrm{ng} / \mathrm{ml}$; GTH, $4 \mathrm{IU} / \mathrm{ml}$ of PMSG and hCG; and BDNF, $30 \mathrm{ng} / \mathrm{ml}$.

$44 \mathrm{~h}$ with or without different doses of recombinant human BDNF (10-40 ng/ml; Sigma), NT-3 (10 ng/ml; Sigma), and NGF (10 ng/ml; Sigma). After IVM, extrusion of the first polar body was observed. The same experiments were replicated using TCM-199 supplemented with $10 \%(\mathrm{v} / \mathrm{v}) \mathrm{pFF}$ instead of PVA. Some COCs were cultured with BDNF $(30 \mathrm{ng} / \mathrm{ml})$ with or without a pan-specific Trk receptor inhibitor, K252a (100 nM; Calbiochem, San Diego, CA, USA) or K252b (100 nM; Calbiochem). After IVM, extrusion of the first polar body was observed and GSH content in the oocytes was assayed to evaluate oocyte maturation.

In experiment 2, the effect of BDNF was investigated following previously reported two-step culture system (Lee et al. 2005) with slight modification. We assigned oocytes into two experimental groups, namely EGFtreated or nontreated. In EGF-treated group, COCs were cultured in TCM-199 supplemented with $10 \mathrm{ng} / \mathrm{ml} \mathrm{EGF,}$ GTH, which consists of $4 \mathrm{IU} / \mathrm{ml}$ pregnant mare serum gonadotropin (PMSG; Intervet, Boxmeer, The Netherlands) and human chorionic gonadotriphin (Intervet), and $10 \%$ pFF. After culturing for $22 \mathrm{~h}$, COCs were washed thrice and cultured in GTH-free TCM-199 medium for another $22 \mathrm{~h}$. The same culture medium excluding EGF was used for EGF nontreated experiment. Supplementation of BDNF $(30 \mathrm{ng} / \mathrm{ml})$ is summarized in
Table 1. After IVM, extrusion of the first polar body was observed to evaluate oocyte maturation.

In experiment 3, oocytes were matured under four different conditions (Table 2), on the basis of results obtained in experiment 2 . They were then subjected to IVF to examine their developmental competence.

In experiment 4, oocytes were matured under four different conditions (Table 3) on the basis of results obtained in experiment 2. They were then used for SCNT to examine their developmental competence.

\section{Statistical analysis}

All data were subjected to one-way ANOVA followed by Tukey's test to determine statistical differences among experimental groups. Statistical significance was determined when $P<0.05$.

\section{Results}

\section{Expression of BDNF and its receptors in porcine oocytes and follicular cells}

Expression of BDNF and its receptors, TrkB, trTrkB, and p75 NTR, was analyzed in porcine oocytes and follicular cells by RT-PCR. Ovarian CDNA was used as a positive control. As shown in Fig. 1, the transcripts of BDNF, trTrkB, and p75 NTR were detected in all samples. However, the mRNA of full-length TrkB was not found in MI stage oocytes although it was detected in follicular cells. In order to confirm and localize this expression, we used immunohistochemical techniques to detect BDNF and TrkB in cultured oocytes and cumulus cells. GTH treatment induced stronger BDNF expression in cultured cumulus cells, while TrkB expression was only slightly detectable, irrespective of GTH treatment (Fig. 2A). Furthermore, expression of BDNF was localized to the chromatin, but no TrkB staining was detected in MI stage oocytes (Fig. 2B). All staining was evidenced by comparison with control experiments with secondary antibody alone, which were negative.

Table 2 Effect of brain-derived neurotropic factor (BDNF) supplementation on the developmental potential of porcine oocytes after in vitro fertilization.

\begin{tabular}{|c|c|c|c|c|c|c|c|}
\hline & \multicolumn{2}{|c|}{ IVM } & \multirow[b]{2}{*}{$\begin{array}{c}\text { Number of } \\
\text { oocytes studied }\end{array}$} & \multirow[b]{2}{*}{$\begin{array}{l}\text { Number }(\%) \text { of } \\
\text { embryos cleaved }\end{array}$} & \multirow[b]{2}{*}{$\begin{array}{l}\text { Number (\% of } \\
\text { total) of embryos } \\
\text { developed to } \\
\text { blastocyst }\end{array}$} & \multirow[b]{2}{*}{$\begin{array}{c}\text { Cell number in } \\
\text { blastocyst } \\
\text { (mean } \pm \text { s.E.M.) }\end{array}$} & \multirow[b]{2}{*}{ Replicate } \\
\hline & $0-22 \mathrm{~h}$ & $22-44 \mathrm{~h}$ & & & & & \\
\hline \multirow[t]{2}{*}{$\mathrm{EGF}(-)$} & GTH & - & 218 & $131(60.1)$ & $34(15.6)^{*}$ & $70.1 \pm 6.2$ & 6 \\
\hline & $\mathrm{GTH}+\mathrm{BDNF}$ & BDNF & 232 & $140(60.3)$ & $28(12.1)^{*}$ & $56.3 \pm 10.0$ & 6 \\
\hline \multirow{2}{*}{$\mathrm{EGF}(+)$} & GTH & - & 371 & $225(60.7)$ & $60(16.2)^{*}$ & $61.9 \pm 10.1$ & 6 \\
\hline & $\mathrm{GTH}+\mathrm{BDNF}$ & BDNF & 244 & 155 (63.5) & $71(29.1)^{+}$ & $67.4 \pm 11.7$ & 6 \\
\hline
\end{tabular}

\footnotetext{
${ }^{*},+$ Within the same column, values with different superscripts were significantly different $(P<0.05)$.
} 
Table 3 Effect of brain-derived neurotropic factor (BDNF) supplementation on developmental potential of porcine oocytes after somatic cell nuclear transfer.

\begin{tabular}{|c|c|c|c|c|c|c|c|c|}
\hline & \multicolumn{2}{|c|}{ IVM } & \multirow[b]{2}{*}{$\begin{array}{l}\text { Number of } \\
\text { oocytes } \\
\text { injected }\end{array}$} & \multirow[b]{2}{*}{$\begin{array}{l}\text { Number }(\%) \text { of } \\
\text { oocytes fused }\end{array}$} & \multirow[b]{2}{*}{$\begin{array}{c}\text { Number }(\%) \text { of } \\
\text { embryos } \\
\text { cleaved }\end{array}$} & \multirow[b]{2}{*}{$\begin{array}{l}\text { Number }(\%) \text { of } \\
\text { embryos } \\
\text { developed to } \\
\text { blastocyst }\end{array}$} & \multirow[b]{2}{*}{$\begin{array}{c}\text { Cell number in } \\
\text { blastocyst } \\
\text { (mean } \pm \text { s.E.M.) }\end{array}$} & \multirow[b]{2}{*}{ Replicate } \\
\hline & $0-22 \mathrm{~h}$ & $22-44 \mathrm{~h}$ & & & & & & \\
\hline \multirow[t]{2}{*}{ EGF $(-)$} & GTH & - & 251 & 168 (66.9) & $95(56.6)$ & $5(3.0)^{*}$ & $46.0 \pm 14.0$ & 6 \\
\hline & GTH+BDNF & BDNF & 297 & $191(64.3)$ & $125(65.5)$ & $17(9.0)^{\dagger}$ & $61.0 \pm 16.7$ & 6 \\
\hline \multirow{2}{*}{$\mathrm{EGF}(+)$} & GTH & - & 255 & $173(67.8)$ & 93 (53.8) & $15(8.7)^{+}$ & $61.3 \pm 8.6$ & 6 \\
\hline & $\mathrm{GTH}+\mathrm{BDNF}$ & BDNF & 293 & 199 (67.9) & $132(66.3)$ & $27(13.6)^{\ddagger}$ & $69.0 \pm 9.6$ & 6 \\
\hline
\end{tabular}

${ }^{*,+, \neq}$ Within the same column, values with different superscripts were significantly different $\left({ }^{*,+} P<0.01 ;{ }^{+, \neq} P<0.01 ;{ }^{*, \neq} P<0.001\right)$.

\section{Effect of BDNF supplementation on nuclear and cytoplasmic maturation of porcine oocytes}

Initially, COCs were cultured in basic TCM-199 media supplemented with $0.1 \%$ PVA and various concentrations of BDNF or other NTs. Under these conditions, only $30 \mathrm{ng} / \mathrm{ml}$ BDNF significantly $(P<0.05)$ increased first polar body extrusion when compared with control (control, 24.0\%; $10 \mathrm{ng} / \mathrm{ml}$ BDNF, 23.2\%; $20 \mathrm{ng} / \mathrm{ml}$ BDNF, 29.2\%; $30 \mathrm{ng} / \mathrm{ml} \mathrm{BDNF,} \mathrm{37.1 \% ;} 40 \mathrm{ng} / \mathrm{ml} \mathrm{BDNF}$, 29.9\%; NGF, 25.1\%; NT-3, 25.6\%; Fig. 3A). We next examined the effect of BDNF on COCs cultured in TCM199 supplemented with $10 \% \mathrm{pFF}$ and added two treatment groups $(25,35 \mathrm{ng} / \mathrm{ml}$ BDNF) to provide confidence in the dose-response data. As shown in Fig. 3B, similar results were obtained where only $30 \mathrm{ng} / \mathrm{ml}$ BDNF significantly $(P<0.05)$ increased first polar body extrusion when compared with control (control, 28.7\%; $10 \mathrm{ng} / \mathrm{ml}$ BDNF, 28.6\%; $20 \mathrm{ng} / \mathrm{ml}$ BDNF, 34.1\%; $25 \mathrm{ng} / \mathrm{ml} \mathrm{BDNF,} \mathrm{34.6 \% ;} 30 \mathrm{ng} / \mathrm{ml} \mathrm{BDNF}$, $46.1 \% ; 35 \mathrm{ng} / \mathrm{ml} \mathrm{BDNF}, 37.7 \% ; 40 \mathrm{ng} / \mathrm{ml} \mathrm{BDNF}, 33.3 \%$; NGF, $28.9 \%$; NT-3, 30.4\%). The effect of BDNF was further confirmed by GSH assay and by using the TrkB receptor inhibitors, K252a, and K252b. During IVM, concurrent treatment of $30 \mathrm{ng} / \mathrm{ml}$ BDNF with K252a, but not the membrane nonsoluble K252b, blocked the effect of BDNF on first polar body extrusion (control, 28.5\%; BDNF, 51.3\%; BDNF + K252a, 27.5\%; BDNF + K252b, 48.3\%; K252a, 26.9\%; K252b, 30.8\%; $P<0.05$; Fig. 4). Moreover, when compared with the control, BDNF (20, 30 , and $40 \mathrm{ng} / \mathrm{ml})$ significantly $(P<0.01)$ increased the GSH content in oocytes (control, $5.8 \mathrm{pmol} ; 10 \mathrm{ng} / \mathrm{ml}$ BDNF, $8.6 \mathrm{pmol} ; 20 \mathrm{ng} / \mathrm{ml}$ BDNF, $11.0 \mathrm{pmol} ; 30 \mathrm{ng} / \mathrm{ml}$ BDNF, 12.7 pmol; 40 ng/ml BDNF, 10.0 pmol; Fig. 5).

When BDNF was applied to the two-step culture system, 44-h treatment of BDNF in the absence of EGF significantly $(P<0.05)$ promoted the meiotic progression of oocytes when compared with BDNF untreated oocytes amongst those groups supplemented with GTH for the first $22 \mathrm{~h}$ of culture (Fig. 6A). However, the effect was diminished with the addition of EGF and no differences were found between groups supplemented with GTH for the first $22 \mathrm{~h}$ of culture (Fig. 6B).

\section{Effect of BDNF supplementation on developmental potential of porcine oocytes after IVF}

Four groups were designed based on the results of Fig. 6A and $B$, to examine the effect of BDNF on the developmental potency of oocytes in the presence or absence of EGF. As shown in Table 2, $30 \mathrm{ng} / \mathrm{ml}$ BDNF in the presence of $10 \mathrm{ng} / \mathrm{ml}$ EGF significantly $(P<0.05)$ increased the rate of blastocyst formation, although no differences in cleavage rates and average blastocyst cell number were observed between the four groups.

\section{Effect of BDNF supplementation on the developmental potential of porcine oocytes after SCNT}

As shown in Table 3, both $30 \mathrm{ng} / \mathrm{ml}$ BDNF and $10 \mathrm{ng} /$ $\mathrm{ml}$ EGF significantly $(P<0.01)$ increased the rate of blastocyst formation of SCNT embryos. When BDNF was added in combination with EGF, blastocyst development was significantly $(P<0.01)$ higher than in the groups treated with BDNF or EGF alone. However, no differences were observed between the four groups in terms of cleavage rates or average cell numbers in blastocysts.

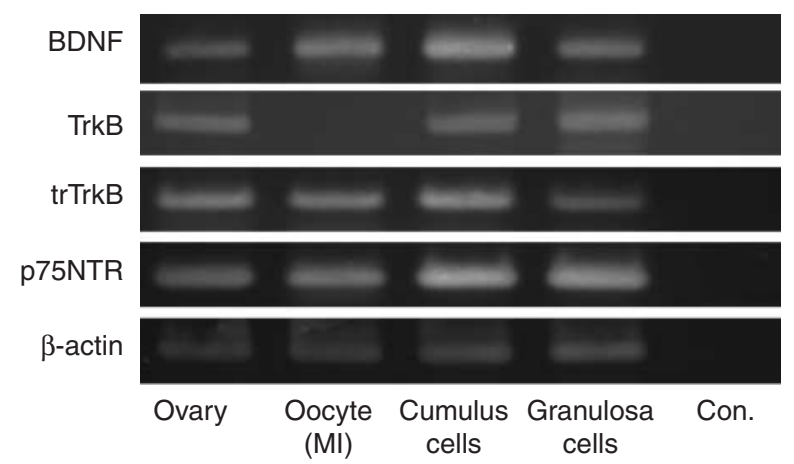

Figure 1 Expression of BDNF, full-length TrkB, truncated TrkB (trTrkB), and p75 NTR mRNAs in porcine isolated ovarian cells and MI stage oocytes was determined by RT-PCR. $\beta$-actin served as a ubiquitously expressed control. Total ovarian mRNAs was used for positive control tests and reactions lacking CDNA showed no PCR amplification products (con). 
A

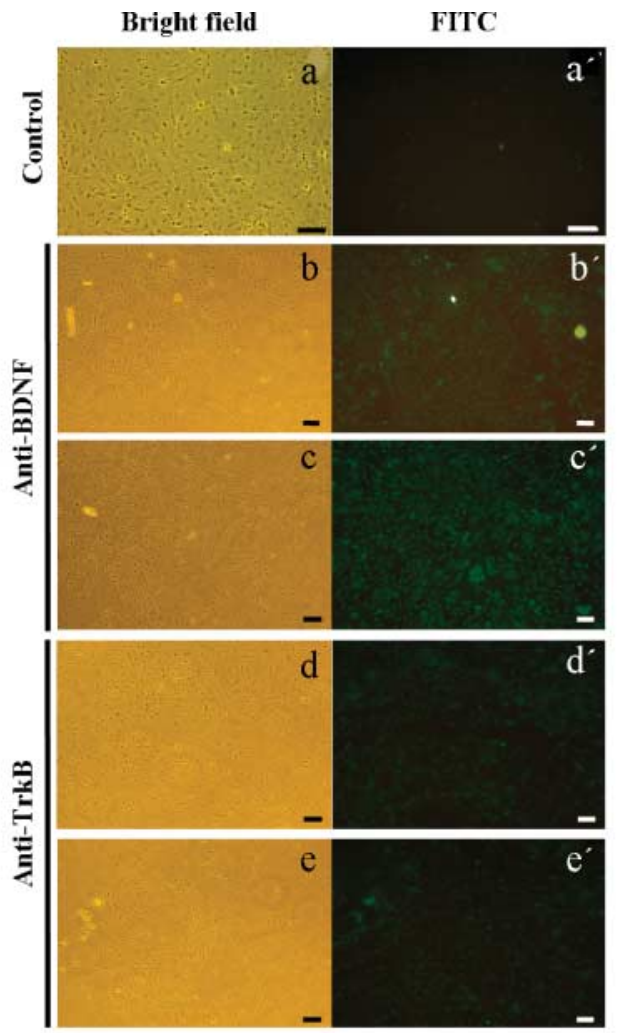

B
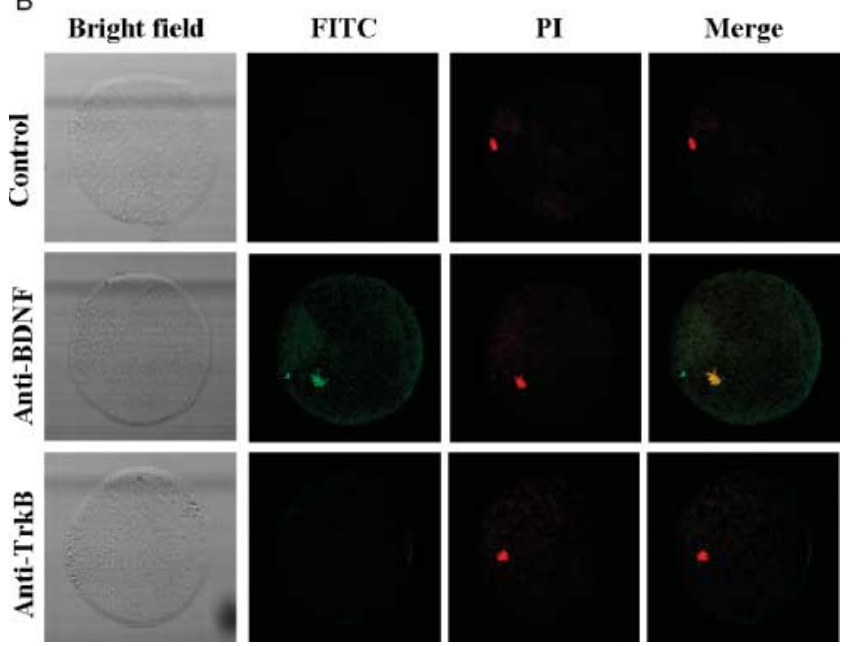

Figure 2 Immunostaining for BDNF and TrkB in porcine cumulus cells (A) and MI stage oocyte (B). Cumulus cells were stained with anti-BDNF or TrkB antibody (green) both before (b and d) and after (c and e) treatment with GTH. MI stage oocyte was obtained $22 \mathrm{~h}$ after IVM and stained with anti-BDNF or TrkB antibody (green). The DNA was counterstained with PI (red). Samples incubated without primary antibody were used as a negative control (control). Scale bar $=10 \mu \mathrm{m}$.

\section{Discussion}

IVM studies of porcine oocytes are of strategic value for research and commercial use. In order to improve the existing porcine IVM system, the present study examined the effect of BDNF on porcine oocyte IVM, since it is thought to be one of several intra-follicular paracrine factors. The main finding of this study is that BDNF enhances nuclear and cytoplasmic maturation by autocrine and/or paracrine signals and increases the developmental potency of embryos after IVF and SCNT.

Although oocyte maturation is triggered by the GTH surge, GTH receptor expression was not detected in either the oocyte itself or its surrounding cumulus cells, but these receptors were expressed in the follicular cells of both theca and granulosa cells (Peng et al. 1991). In this context, Ackland et al. (1992) previously reported that some paracrine factors, which accumulate in follicular fluid in response to GTH, may affect oocyte maturation. Thus, we propose that these factors could be used in an IVM system, and would be expected to improve its efficiency. However, with the exception of EGF, IGF-I, and IGF-II there is only limited information on the nature of ovarian factors which could have a stimulating effect on porcine oocyte IVM (Ding \& Foxcroft 1994, Sirotkin et al. 2000).

Based on their expression and substantial roles in the mammalian ovary (Dissen et al. 1996, 2002, Spears et al. 2003), several investigations have reported that various NTs and their respective receptor tyrosine kinases could enhance the IVM of oocytes from different species. For example, NGF treatment promoted ovine oocyte GVBD (Barboni et al. 2002) and both NT-4/5 and BDNF were shown to play a paracrine role in enhancing polar body extrusion in mouse oocytes (Seifer et al. 2002a, 2002b). Furthermore, the maturation of oocytes in the presence of BDNF promoted the preimplantational development of mouse (Kawamura et al. 2005) and bovine (Martins da Silva et al. 2005) embryos.

In the mouse study, BDNF transcripts were expressed in follicular cells, while TrkB and p75 NTR expression was detected exclusively in oocytes (Kawamura et al. 2005). However, in the bovine study, BDNF and p75 NTR mRNA was detected in both cumulus cells and oocytes, whereas TrkB showed a similar pattern of expression to that of mouse (Martins da Silva et al. 2005). As shown in Fig. 1, our current study provided evidence that the transcripts of BDNF, trTrkB, and p75 NTR were detected in all samples, whereas the mRNA of full-length TrkB was not found in MI stage oocyte but detected in follicular cells. Immunohistochemistry, which was used to confirm the localization of BDNF and TrkB proteins, showed immunopositivity for both proteins in cultured cumulus cells. TrkB expression was only slightly detectable in cumulus cells, regardless of GTH treatment, but stronger BDNF expression was induced after GTH treatment (Fig. 2A). This suggests the stimulated expression of BDNF by GTH in porcine ovarian follicles. In addition, BDNF expression was confirmed in the chromatin of oocytes, but no TrkB staining was detected in MI stage oocytes (Fig. 2B). The functions of truncated isoforms of the TrkB receptor, which lack the intracellular domain, but retain the ligand-binding domain 
(a)

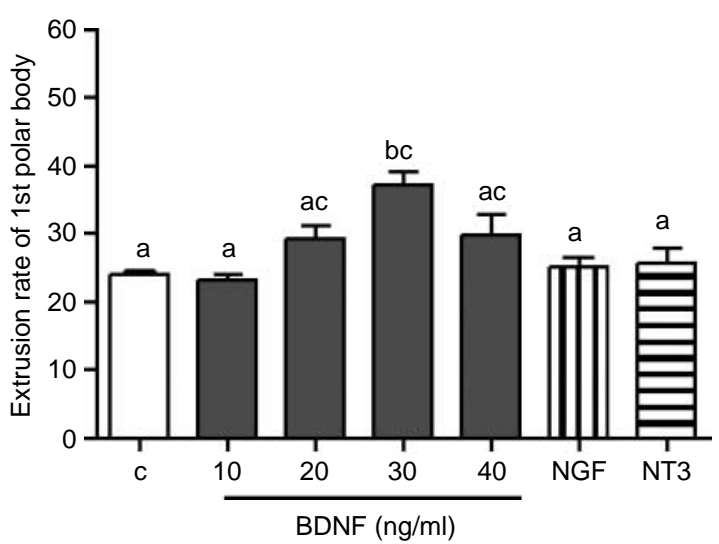

(b)

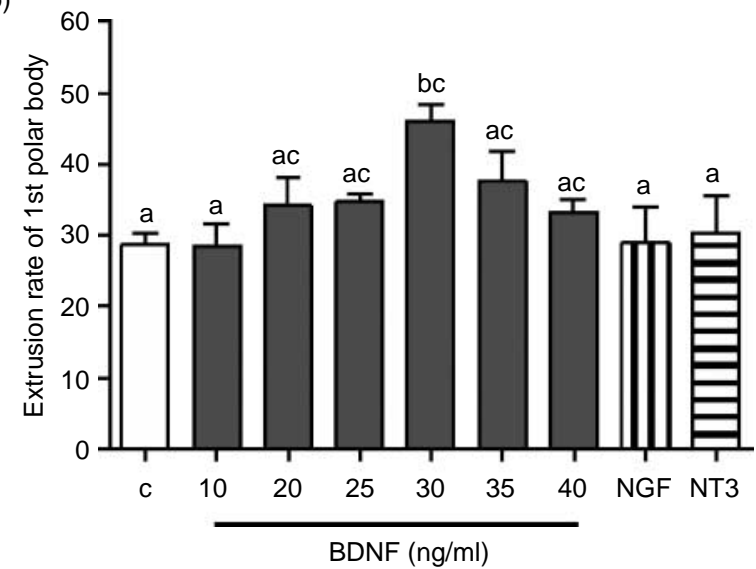

Figure 3 Effect of BDNF supplementation on first polar body extrusion of porcine oocytes (mean \pm S.E.M). COCs were cultured without (control, c) or with different doses of BDNF. Some COCs were cultured with NGF $(10 \mathrm{ng} / \mathrm{ml})$ and NT-3 $(10 \mathrm{ng} / \mathrm{ml})$. COCs were cultured in TCM-199 supplemented with $0.1 \%$ PVA (A) or TCM-199 supplemented with $10 \% \mathrm{pFF}$ (B). Five replications and between 280 and 350 oocytes for each of the seven treatment groups (A) or between 280 and 450 oocytes for each of the nine treatment groups (B) were used for each experiment. Different letters denote significant differences $(P<0.05)$.

(Klein et al. 1990), are unclear. Consistent with our findings, in mouse, low levels of full-length TrkB receptors are detected in oocytes at all phases of follicular development, but they can be detected in granulosa cells only in growing follicles (Paredes et al. 2004). Furthermore, the finding that the majority of the TrkB receptors detected in the growing oocyte's cell membrane are truncated suggests that truncated TrkB receptors might be important for oocyte survival (Paredes et al. 2004). On the basis of these results, we can hypothesize that the mechanism of action of BDNF in porcine could be bidirectional with autocrine and/or paracrine signals being relayed between cumulus cells and oocytes. Their complex interactions and functional differences remain to be resolved.

Based upon the expression patterns, we analyzed the effect of BDNF on IVM of porcine oocytes to determine whether it could improve in vitro production (IVP)

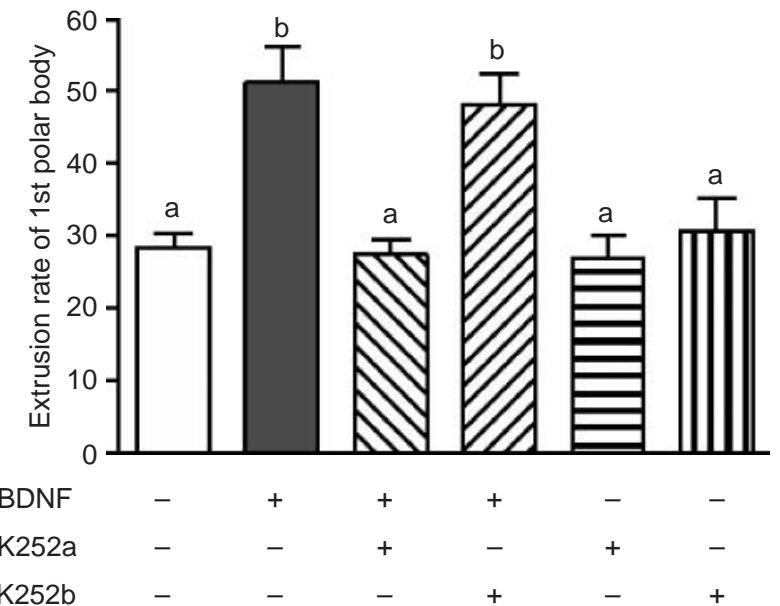

Figure 4 Effect of Trk receptor inhibitor K252a or K252b on first polar body extrusion of porcine oocytes (mean \pm S.E.M). COCs were cultured in TCM-199 supplemented with $10 \% \mathrm{pFF}$ with or without BDNF (30 ng/ml), K252a (100 nM) or K252b (100 nM). Four replications and between 249 and 303 oocytes for each of the six treatment groups were used. Different letters denote significant differences $(P<0.05)$.

efficiency. Extrusion of first polar bodies and oocyte GSH levels were used to evaluate nuclear and cytoplasmic maturation of oocytes respectively. GSH is known to be an important intra-oocyte factor for supporting events after fertilization, such as decondensation of sperm nuclei and male pronuclear formation (Perreault et al. 1988, Yoshida et al. 1993). As shown in Fig. 3A, $30 \mathrm{ng} / \mathrm{ml}$ BDNF significantly $(P<0.05$, when compared with control) increased the rate of first polar body extrusion in oocytes cultured in TCM-199 media supplemented with $0.1 \%$ PVA, whereas other BDNF concentrations and the NTs, NGF, and NT-3 were without effect. There were no

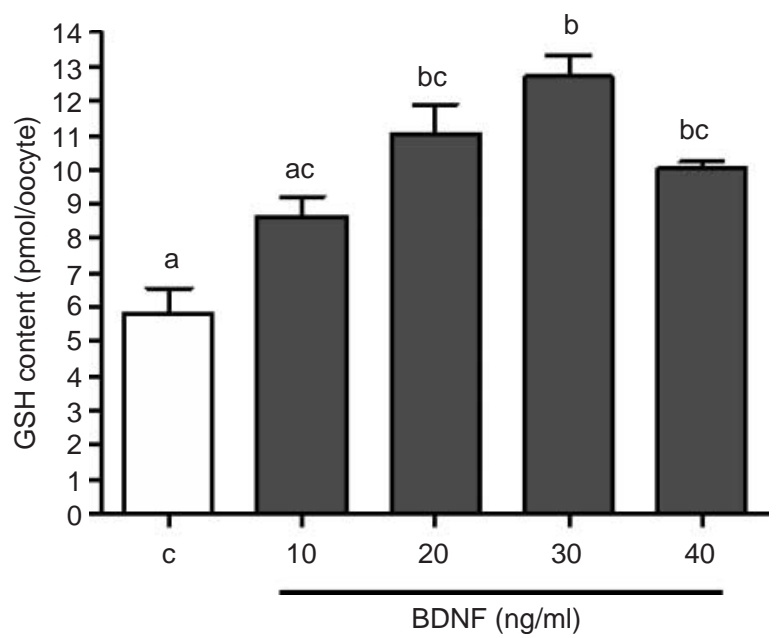

Figure 5 Effect of BDNF supplementation on GSH content in porcine oocytes (mean \pm s.E.M). COCs were cultured in TCM-199 supplemented with $10 \%$ pFF with or without (control, c) different doses of BDNF. Five replications and between 150 and 200 oocytes for each of the five treatment groups were used. Different letters denote significant differences $(P<0.01)$. 

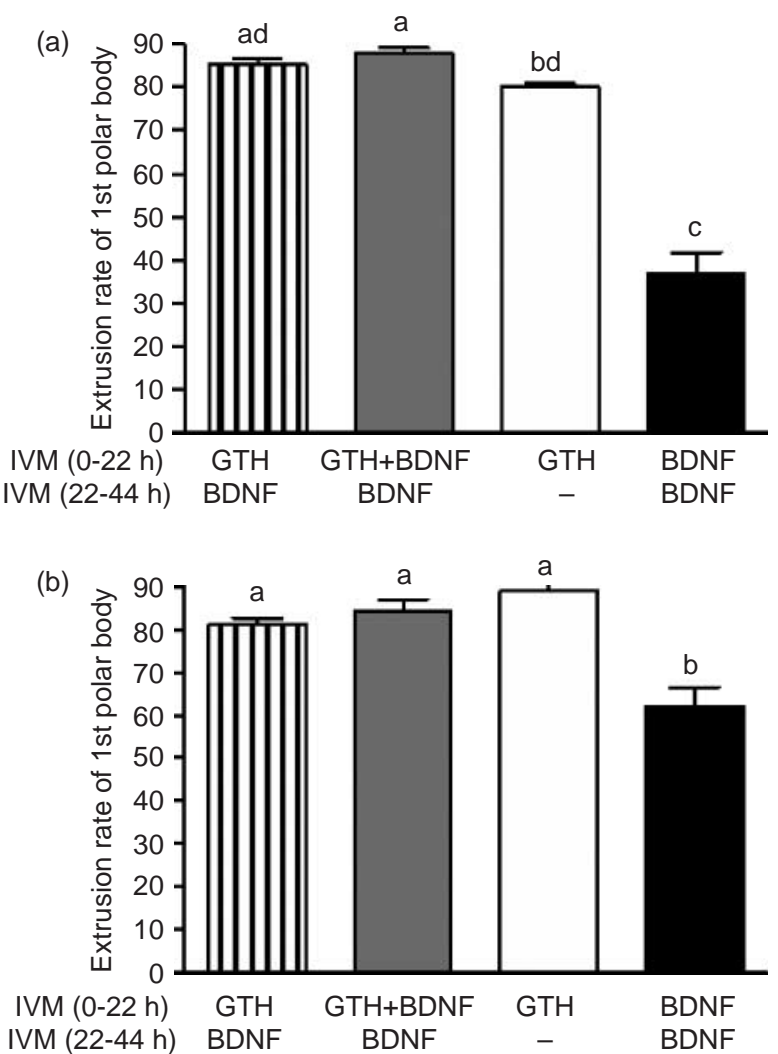

Figure 6 Effect of BDNF supplementation on first polar body extrusion of porcine oocytes (mean \pm s.E.M). COCs were cultured in two-step culture system without (A) or with (B) EGF. Effect of BDNF on the latter $22 \mathrm{~h}$ (vertical striped bar) or entire $44 \mathrm{~h}$ (gray bar) of IVM was investigated. One-step culture group with BDNF (black bar) was used as control. Five replications and between 181 and 237 oocytes for each of the four treatment groups were used for each experiment $(A$ and $B)$. Different letters denote significant differences $\left({ }^{\mathrm{a}, \mathrm{b}} P<0.05 ;{ }^{\mathrm{a}, \mathrm{c}} P<0.001\right.$; $\left.{ }_{\mathrm{b}, \mathrm{c}} \mathrm{P}<0.001\right)$.

significant differences observed at either 20 or $40 \mathrm{ng} / \mathrm{ml}$ of BDNF supplementation. In order to clarify if only such a precise concentration of BDNF has an effect on nuclear maturation, we added two treatment groups ( 25 and $35 \mathrm{ng} /$ $\mathrm{ml}$ ) in the next study. In addition, although PVA was used for initial study to exclude the effect of inherent NTs in pFF, supplementation of PVA was insufficient to substitute the known benefit of pFF in oocyte maturation. Thus, we next examined the effect of BDNF on COCs cultured in TCM199 supplemented with $10 \%$ pFF. As shown in Fig. 3B, similar results were obtained where only $30 \mathrm{ng} / \mathrm{ml}$ BDNF significantly $(P<0.05)$ increased first polar body extrusion when compared with control with no effect on other tested concentrations. Further investigation including determination of the physiological level of BDNF in porcine species would be required to explain this phenomenon. The increase rate of meiotic maturation with $30 \mathrm{ng} / \mathrm{ml} \mathrm{BDNF}$ is comparable between the two experiments (from 24 to $37.1 \%, 155 \%$ increase, + PVA; from 28.7 to $46.1 \%, 161 \%$ increase, + pFF).
The role of the TrkB receptor in mediating this effect was demonstrated using the Trk receptor inhibitor K252a. Supplementing BDNF treatment with K252a, but not the membrane nonsoluble K252b, during IVM blocked the effect of BDNF on first polar body extrusion (Fig. 4). In agreement with the nuclear maturation observations, $30 \mathrm{ng} / \mathrm{ml}$ BDNF significantly $(P<0.01)$ increased GSH content in oocytes, when compared with controls (Fig. 5). Thus, we used $30 \mathrm{ng} / \mathrm{ml} \mathrm{BDNF}$ for further studies.

Next, BDNF was applied to the two-step culture IVM system, in which oocytes are cultured in GTH for an initial $22 \mathrm{~h}$ and then in GTH-free medium for a further $22 \mathrm{~h}$. We assigned oocytes into two experimental groups, namely EGF-treated or nontreated, because both BDNF and EGF activate receptor tyrosine kinases. This raises the possibility that they could act either competitively or synergistically. We investigated the effect of BDNF on both the entire $44 \mathrm{~h}$ and latter $22 \mathrm{~h}$ of IVM in the presence and absence of EGF (Table 1). When EGF was omitted from culture medium, 44-h treatment of BDNF significantly $(P<0.05)$ promoted the nuclear maturation of oocytes when compared with BDNF untreated oocytes amongst groups supplemented with GTH for the first $22 \mathrm{~h}$ of culture (Fig. 6A). However, the effect was diminished with the addition of EGF such that no differences were found between groups supplemented with GTH for the first $22 \mathrm{~h}$ of culture (Fig. 6B).

Although no differences were observed between BDNF-treated groups in the presence of GTH, whether EGF was added or not, we choose those groups treated with BDNF for the entire duration of two-step culture for further study, because their nuclear maturation was slightly better than that of the groups treated with BDNF for only the latter period. We next evaluated the effect of BDNF on developmental competence of oocytes after IVF and SCNT.

In the presence of EGF, treatment with BDNF during IVM significantly $(P<0.05)$ increased the developmental competence of embryos to blastocyst stage after IVF. Moreover, since this was not observed with either BDNF or EGF alone, it must reflect a stimulatory interaction between BDNF and EGF. Notably, we failed to observe the previously reported promoting effect of EGF on the developmental competence of porcine IVF embryos (Abeydeera et al. 1998). However, in the case of SCNT, a single treatment of BDNF or EGF did significantly $(P<0.01)$ enhance the developmental potency of embryos to blastcyst stage (Table 3). This result indicates that the addition of EGF during IVM can influence the blastocyst formation of porcine SCNT embryos and that BDNF can substitute for this effect. Also, combined treatment with BDNF and EGF significantly $(P<0.01)$ increased blastocyst development of SCNT embryos when compared with the single treatment groups, similar to the stimulatory effect observed in the IVF experiment. Meanwhile, in both IVF and SCNT studies, no differences 
were observed between the four groups in either cleavage rates or the number of blastocyst cells.

Although TrkB and the EGF receptor have different ligand-binding domains on the outer surface of the plasma membrane, both are receptor tyrosine kinases and act through similar intracellular signaling pathways (Alberts et al. 2002). In fact, stimulatory crosstalk between EGF and IGF-I signaling, which is also mediated through receptor tyrosine kinase activity, has been well described. In certain cell types, the EGF receptor can transactivate the IGF-I receptor (Burgaud \& Baserga 1996), and the IGF-I receptor was able to activate some important members of the EGF-signaling pathway (Roudabush et al. 2000). Thus, the observed effects of combined BDNF and EGF treatment on blastocyst development in IVF and SCNT embryos suggest the existence of a synergetic interaction between BDNF and EGF.

In the present study, concurrent treatment of BDNF with EGF increased the rate of embryos developed to the blastocyst stage after both IVF and SCNT. However, no differences were observed when we examined the kinetics of meiotic maturation under the same culture conditions (Fig. 6B). Similarly, it has been reported that the addition of EGF did not increase the proportion of oocytes maturing to MII stage but did increase developmental ability of embryos after IVF in mouse (Merriman et al. 1998) and pig (Abeydeera et al. 1998). In addition, a recent study using bovine oocytes demonstrated that BDNF may benefit oocyte competence for embryo development without necessarily benefiting nuclear maturation (Martins da Silva et al. 2005). Cytoplasmic maturation more generally refers to those other maturational events that occur in the oocyte, necessary for the acquisition of developmental competence but not directly related to meiotic progression, and can probably occur independent of nuclear maturation (Eppig 1996). This possibly explains why only $30 \mathrm{ng} / \mathrm{ml}$ BDNF was effective in increasing nuclear maturation, whereas $20-40 \mathrm{ng} / \mathrm{ml}$ increased GSH content in oocytes.

In conclusion, when administered during IVM, BDNF increased both nuclear and cytoplasmic maturation of porcine oocytes via autocrine and/or paracrine signals between the cumulus and oocytes. Furthermore, BDNF, together with EGF, enhanced the blastocyst development of oocytes after IVF and SCNT, demonstrating an improved IVP protocol for porcine oocytes.

\section{Acknowledgement}

The authors declare that there is no conflict of interest that would prejudice the impartiality of this scientific work.

\section{References}

Abeydeera LR, Wang WH, Cantley TC, Rieke A, Prather RS \& Day BN 1998 Presence of epidermal growth factor during in vitro maturation of pig oocytes and embryo culture can modulate blastocyst development after in vitro fertilization. Molecular Reproduction and Development 51 395-401.

Ackland JF, Schwartz NB, Mayo KE \& Dodson RE 1992 Nonsteroidal signals originating in the gonads. Physiological Reviews 72 731-787.

Alberts B, Johnson A, Lewis J, Raff M, Roberts K, Walter P 2002 Molecular Biology of the Cell, 4. pp. 871-882. Garland Science New York.

Anderson RA, Robinson LL, Brooks J \& Spears N 2002 Neurotropins and their receptors are expressed in the human fetal ovary. Journal of Clinical Endocrinology and Metabolism 87 890-897.

Baker MA, Cerniglia GJ \& Zaman A 1990 Microtiter plate assay for the measurement of glutathione and glutathione disulfide in large numbers of biological samples. Analytical Biochemistry 190 $360-365$.

Barboni B, Mattioli M, Gioia L, Turriani M, Capacchietti G, Berardinelli P \& Bernabo N 2002 Preovulatory rise of NGF in ovine follicular fluid: possible involvement in the control of oocyte maturation. Microscopy Research and Technique 59 516-521.

Burgaud JL \& Baserga R 1996 Intracellular transactivation of the insulin-like growth factor I receptor by an epidermal growth factor receptor. Experimental Cell Research 223 412-419.

Day BN 2000 Reproductive biotechnologies: current status in porcine reproduction. Animal Reproduction Science 60-61 161-172.

Ding J \& Foxcroft GR 1994 Epidermal growth factor enhances oocyte maturation in pigs. Molecular Reproduction and Development 39 $30-40$.

Dissen GA, Hill DF, Costa ME, Les Dees CW, Lara HE \& Ojeda SR 1996 A role for trkA nerve growth factor receptors in mammalian ovulation. Endocrinology 137 198-209.

Dissen GA, Romero C, Paredes A \& Ojeda SR 2002 Neurotrophic control of ovarian development. Microscopy Research and Technique 59 509-515.

Eppig JJ 1996 Coordination of nuclear and cytoplasmic oocyte maturation in eutherian mammals. Reproduction, Fertility, and Development 8 485-489.

Jones KR, Farinas I, Backus C \& Reichardt LF 1994 Targeted disruption of the $B D N F$ gene perturbs brain and sensory neuron development but not motor neuron development. Cell 76 989-999.

Kawamura K, Kawamura N, Mulders SM, Gelpke MD \& Hsueh AJ 2005 Ovarian brain-derived neurotrophic factor (BDNF) promotes the development of oocytes into preimplantation embryos. PNAS 102 9206-9211.

Kim HS, Lee GS, Hyun SH, Lee SH, Nam DH, Jeong YW, Kim S, Kang SK, Lee BC \& Hwang WS 2004 Improved in vitro development of porcine embryos with different energy substrates and serum. Theriogenology 61 1381-1393.

Klein R, Conway D, Parada LF \& Barbacid M 1990 The trkB tyrosine protein kinase gene codes for a second neurogenic receptor that lacks the catalytic kinase domain. Cell 61 647-656.

Lee GS, Kim HS, Hyun SH, Jeon HY, Nam DH, Jeong YW, Kim S, Kim JH, Kang SK, Lee BC \& Hwang WS 2005 Effect of epidermal growth factor in preimplantation development of porcine cloned embryos. Molecular Reproduction and Development 71 45-51.

Martins da Silva SJ, Gardner JO, Taylor JE, Springbett A, De Sousa PA \& Anderson RA 2005 Brain-derived neurotrophic factor promotes bovine oocyte cytoplasmic competence for embryo development. Reproduction 129 423-434.

Merriman JA, Whittingham DG \& Carroll J 1998 The effect of follicle stimulating hormone and epidermal growth factor on the developmental capacity of in vitro matured mouse oocytes. Human Reproduction 13 690-695.

Nagai T 2001 The improvement of in vitro maturation systems for bovine and porcine oocytes. Theriogenology 55 1291-1301. 
Ojeda SR, Romero C, Tapia V \& Dissen GA 2000 Neurotrophic and cell-cell dependent control of early follicular development. Molecular and Cellular Endocrinology 163 67-71.

Paredes A, Romero C, Dissen GA, DeChiara TM, Reichardt L, Cornea A, Ojeda SR \& Xu B 2004 TrkB receptors are required for follicular growth and oocyte survival in the mammalian ovary. Developmental Biology 267 430-449.

Peng XR, Hsueh AJ, LaPolt PS, Bjersing L \& Ny T 1991 Localization of luteinizing hormone receptor messenger ribonucleic acid expression in ovarian cell types during follicle development and ovulation. Endocrinology 129 3200-3207.

Perreault SD, Barbee RR \& Slott VL 1988 Importance of glutathione in the acquisition and maintenance of sperm nuclear decondensing activity in maturing hamster oocytes. Developmental Biology 125 181-186.

Roudabush FL, Pierce KL, Maudsley S, Khan KD \& Luttrell LM 2000 Transactivation of the EGF receptor mediates IGF-1-stimulated shc phosphorylation and ERK1/2 activation in COS-7 cells. Journal of Biological Chemistry 275 22583-22589.

Seifer DB, Feng B, Shelden RM, Chen S \& Dreyfus CF 2002a Neurotrophin-4/5 and neurotrophin-3 are present within the human ovarian follicle but appear to have different paracrine/autocrine functions. Journal of Clinical Endocrinology and Metabolism 87 4569-4571.
Seifer DB, Feng B, Shelden RM, Chen S \& Dreyfus CF 2002b Brainderived neurotrophic factor: a novel human ovarian follicular protein. Journal of Clinical Endocrinology and Metabolism 87 655-659.

Sirotkin AV, Dukesova J, Makarevich AV, Kubek A \& Bulla J 2000 Evidence that growth factors IGF-I, IGF-II and EGF can stimulate nuclear maturation of porcine oocytes via intracellular protein kinase A. Reproduction, Nutrition, Development 40 559-569.

Spears N, Molinek MD, Robinson LL, Fulton N, Cameron H, Shimoda K, Telfer EE, Anderson RA \& Price DJ 2003 The role of neurotrophin receptors in female germ-cell survival in mouse and human. Development 130 5481-5491.

Sun QY \& Nagai T 2003 Molecular mechanisms underlying pig oocyte maturation and fertilization. Journal of Reproduction and Development 49 347-359.

Yoshida M, Ishigaki K, Nagai T, Chikyu M \& Pursel VG 1993 Glutathione concentration during maturation and after fertilization in pig oocytes: relevance to the ability of oocytes to form male pronucleus. Biology of Reproduction 49 89-94.

Received 22 October 2006

First decision 21 December 2006

Revised manuscript received 4 May 2007

Accepted 29 May 2007 